\title{
Real-time measurement of adenosine and ATP release in the central nervous system
}

\author{
Nicholas Dale ${ }^{1}$ (10 \\ Received: 4 September 2020 / Accepted: 13 September 2020 / Published online: 6 October 2020 \\ (C) The Author(s) 2020
}

\begin{abstract}
This brief review recounts how, stimulated by the work of Geoff Burnstock, I developed biosensors that allowed direct real-time measurement of ATP and adenosine during neural function. The initial impetus to create an adenosine biosensor came from trying to understand how ATP and adenosine-modulated motor pattern generation in the frog embryo spinal cord. Early biosensor measurements demonstrated slow accumulation of adenosine during motor activity. Subsequent application of these biosensors characterized real-time release of adenosine in in vitro models of brain ischaemia, and this line of work has recently led to clinical measurements of whole blood purine levels in patients undergoing carotid artery surgery or stroke. In parallel, the wish to understand the role of ATP signalling in the chemosensory regulation of breathing stimulated the development of ATP biosensors. This revealed that release of ATP from the chemosensory areas of the medulla oblongata preceded adaptive changes in breathing, triggered adaptive changes in breathing via activation of P2 receptors, and ultimately led to the discovery of connexin26 as a channel that mediates $\mathrm{CO}_{2}$-gated release of ATP from cells.
\end{abstract}

Keywords Biosensor $\cdot$ Ischaemia $\cdot$ Motor pattern generation $\cdot$ Chemosensory $\cdot$ Breathing $\cdot$ Connexin

\section{Introduction}

I vividly remember the first time I heard Geoff Burnstock give a seminar. It was in 1994, and although I had known Geoff for quite some time, I had never heard him deliver a lecture. So, when he came to Bristol to give a major talk, I went with great eagerness, but also not knowing quite what to expect. What unfolded over the course of about an hour was one of the most inspiring lectures I had ever heard. At the time I had only a dim, verging on nonexistent, grasp of purinergic signalling. Geoff, at the height of his powers, convinced me, and I suspect everyone else in the audience that the purines were pretty much the answer to every physiological problem out there. I was so inspired that I got into my lab the very next day and started dabbling with ATP and adenosine. I had been running my own independent lab for about 5 years. I was working on the neuronal mechanisms of spinal motor pattern generation in

This article is part of the Topical Collection on A Tribute to Professor Geoff Burnstock.

Nicholas Dale

n.e.dale@warwick.ac.uk

1 School of Life Sciences, University of Warwick, Coventry CV4 7AL, UK the frog embryo, trying to build Hodgkin-Huxley inspired models of the circuit, so it was natural to apply ATP and adenosine to the spinal cord and look at the consequences for motor pattern generation. Immediately I realized that there was something very interesting: both ATP and adenosine had powerful but opposing actions, on the neural circuitry that generated the swimming motor pattern. Two years of hard work, and self-tuition in the arts of purinergic signalling, resulted in a paper that described an excitatory action of ATP (mediated via an effect of voltage gated $\mathrm{K}^{+}$channels) and an inhibitory action of adenosine (through inhibition of voltage gated $\mathrm{Ca}^{2+}$ channels via $\mathrm{A} 1$ receptors) [1]. It was clear that the inhibitory action of adenosine had something to do with controlling the spontaneous slowing of the swimming motor pattern and its eventual termination. Courtesy of Geoff's great lecture, and subsequent reading of the literature, I was also aware that the adenosine might arise from conversion of ATP that had been released into the extracellular space [2]. This led to a puzzle: if the released ATP, which was excitatory, was converted to adenosine, which was inhibitory, how did this give rise to the observed temporal control of motor pattern generation? One way that this could arise would be if the production of adenosine was delayed with respect to the release of ATP. In fact, there was already a mechanism in the literature whereby ATP and ADP could inhibit the ecto-5'- 
nucleotidase that converts AMP to adenosine that could introduce such a hypothesized delay [3-5]. It was these thoughts that led me to the realization that I needed to test these ideas by measuring the release of adenosine in real time. After further scanning of the literature, I realized that the only way to achieve this was to invent a biosensor for adenosine. What follows is a not a scholarly review of purine measurements, but a personal account of some of the science, in which I have been involved, which flowed from the inspiration that Geoff's talk gave me.

\section{Real-time measurement of adenosine}

To make a biosensor for adenosine, I borrowed from nature the enzymes that are involved in processing purines: adenosine deaminase, purine nucleoside phosphorylase, and xanthine oxidase [6]. This cascade will successively convert adenosine via inosine, hypoxanthine, and xanthine to uric acid. Xanthine oxidase produces $\mathrm{H}_{2} \mathrm{O}_{2}$, which is easy to detect electrochemically (Fig. 1a). Of course, a biosensor that involves 3 enzymes will be sensitive to substrates for all 3 enzymes, so to test whether it specifically detected adenosine, I utilized an inhibitor of adenosine deaminase, coformycin. To make the biosensor, I loaded these three enzymes in aqueous solution into a very fragile microdialysis electrode assembly
(Fig. 1b). The idea was that adenosine, released from tissue, would diffuse through the dialysis membrane, be metabolized by the enzymes within the electrode, and thus generate the $\mathrm{H}_{2} \mathrm{O}_{2}$ for electrochemical detection via the internal electrodes (Fig. 1b, c). This assembly, at $250 \mu \mathrm{m}$ in diameter, was bigger than the spinal cord I was trying to measure from (diameter about $70 \mu \mathrm{m}$ ), and at first, I saw nothing. But one day, after numerous attempts, I detected an adenosine signal. By chance it turned out that the assembly I had used that day had the Pt wire for detecting the $\mathrm{H}_{2} \mathrm{O}_{2}$ in a position that led to it being right next to the spinal cord (Fig. 1c). Reliable detection of adenosine was accomplished once I had convinced the manufacturer of the microdialysis assembly to make them all with that particular arrangement of the internal electrodes (Fig. 1d). My recordings showed that adenosine was produced gradually during motor activity and gave experimental support for the hypothesis of delayed production in the extracellular space [6, 7].

I realized that the adenosine biosensor was potentially quite useful and thought that finding a few collaborators to pursue other questions would be interesting. So, once again, I turned to Geoff and asked him who he thought might be worth contacting. Geoff suggested that his colleague, Mike Spyer, a physiologist at UCL with wide interests in autonomic control who at the time was in the Royal Free Medical School and had an office close to Geoff's, would be good to talk to. This

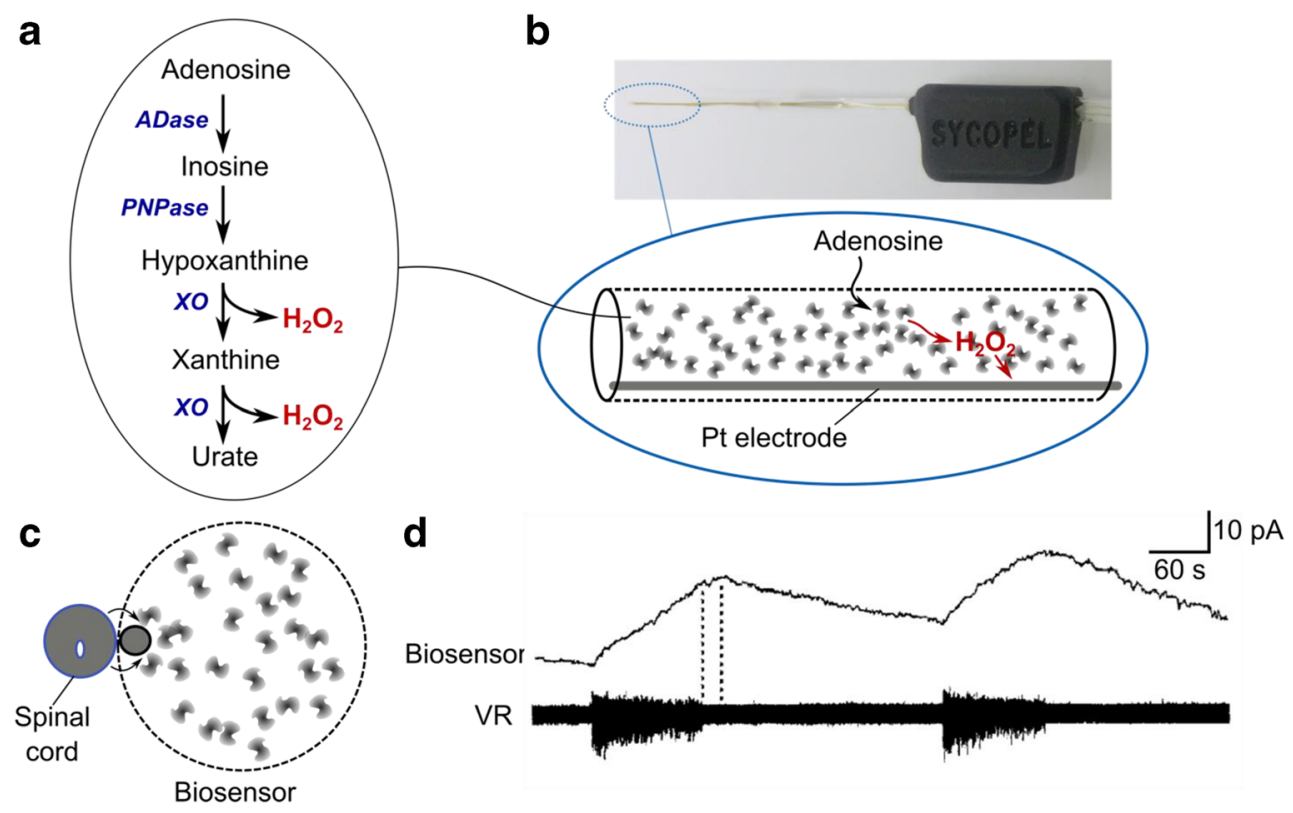

Fig. 1 First real-time recording of adenosine during neural activity. (a) Enzymatic cascade for the adenosine biosensor. ADase, adenosine deaminase; PNPase, purine nucleoside phosphorylase; XO, xanthine oxidase. (b) Image of the microdialysis electrode assembly use for the original adenosine biosensor with schematic showing enzymes in solution, supporting the production of $\mathrm{H}_{2} \mathrm{O}_{2}$ in proportion to the concentration of adenosine (able to diffuse through the porous wall of the electrode) which was detected by the Pt electrode held at $650 \mathrm{mV}$ with respect to an $\mathrm{Ag} / \mathrm{AgCl}$ reference. (c) Schematic of arrangement for recording adenosine release during fictive swimming in the tadpole. The biosensor and spinal cord are shown in cross section to show their relative sizes. Diffusion of adenosine from the spinal cord to the biosensor is indicated by arrows; note that the position of the Pt electrode inside the microdialysis tube was crucial to enable reliable detection. (d) Recording of the real-time release of adenosine during swimming acting indicated by motor nerve activity on the ventral root (VR). Trace reproduced from reference [6] 
was an inspired recommendation, as Mike Spyer had seen my adenosine biosensor paper and had already written to me. Courtesy of a recommendation from Charles Kennedy, I also met up with Bruno Frenguelli, then at Dundee, to discuss collaborations. My collaborations with Mike Spyer and Bruno Frenguelli turned out to be long lasting, fun, very productive, and instrumental in providing the scientific stimulus to develop further the biosensor technology for adenosine and ultimately a biosensor for ATP and other neuroactive compounds.

\section{Measurement of adenosine release: in vitro stroke models to clinical studies}

At the time that Bruno Frenguelli and I started to collaborate in early 1998, Bruno's interest was in how the brain dealt with metabolic stress. Bruno had developed an in vitro model of a stroke in a dish, whereby a hippocampal brain slice could be starved of $\mathrm{O}_{2}$ (hypoxia) or in a more severe model deprived simultaneously of $\mathrm{O}_{2}$ and glucose ("ischaemia"). Recording of synaptic transmission within the slice (the hippocampus with its well-understood neuronal architecture and synaptic connectivity being very advantageous for this) allowed a physiological read-out of the effect of hypoxia/ischaemia. It was known from work of many investigators that, during hypoxia/ischaemia, adenosine was released from neural tissue [8-16]. This work mainly used microdialysis or related techniques to collect perfusate and then analyze this post hoc via HPLC - a laborious and time-consuming enterprise. Bruno and others had pharmacological evidence in vitro that the depression of synaptic transmission during hypoxia/ ischaemia was mediated via adenosine A1 receptors. Thus, when we started to work together, we had a clear expectation that we should see adenosine release during the hypoxic/ ischemic episodes. The advantage of using a biosensor was that we could not only detect the release of adenosine but also examine its effect on synaptic transmission in real time. Our recordings allowed us to determine the temporal relationship between adenosine and its action on synaptic transmission (Fig. 2a), to show that adenosine release did not require extracellular $\mathrm{Ca}^{2+}$ and that the amount of adenosine depleted with successive hypoxic/ischaemic episodes [17, 20].

Nevertheless, although we had the best, and at the time only, real-time method of measuring adenosine release, our work together made us realize the limitations of what we had. The biosensors were big and bulky, very fragile, and difficult to use. The size and fragility meant that we were unable to put the sensors into the tissue (something referees of our papers were very keen for us to do)instead we had to lay them on top. It was these limitations that drove development of better, smaller, more sensitive, and faster responding biosensors. The first-generation
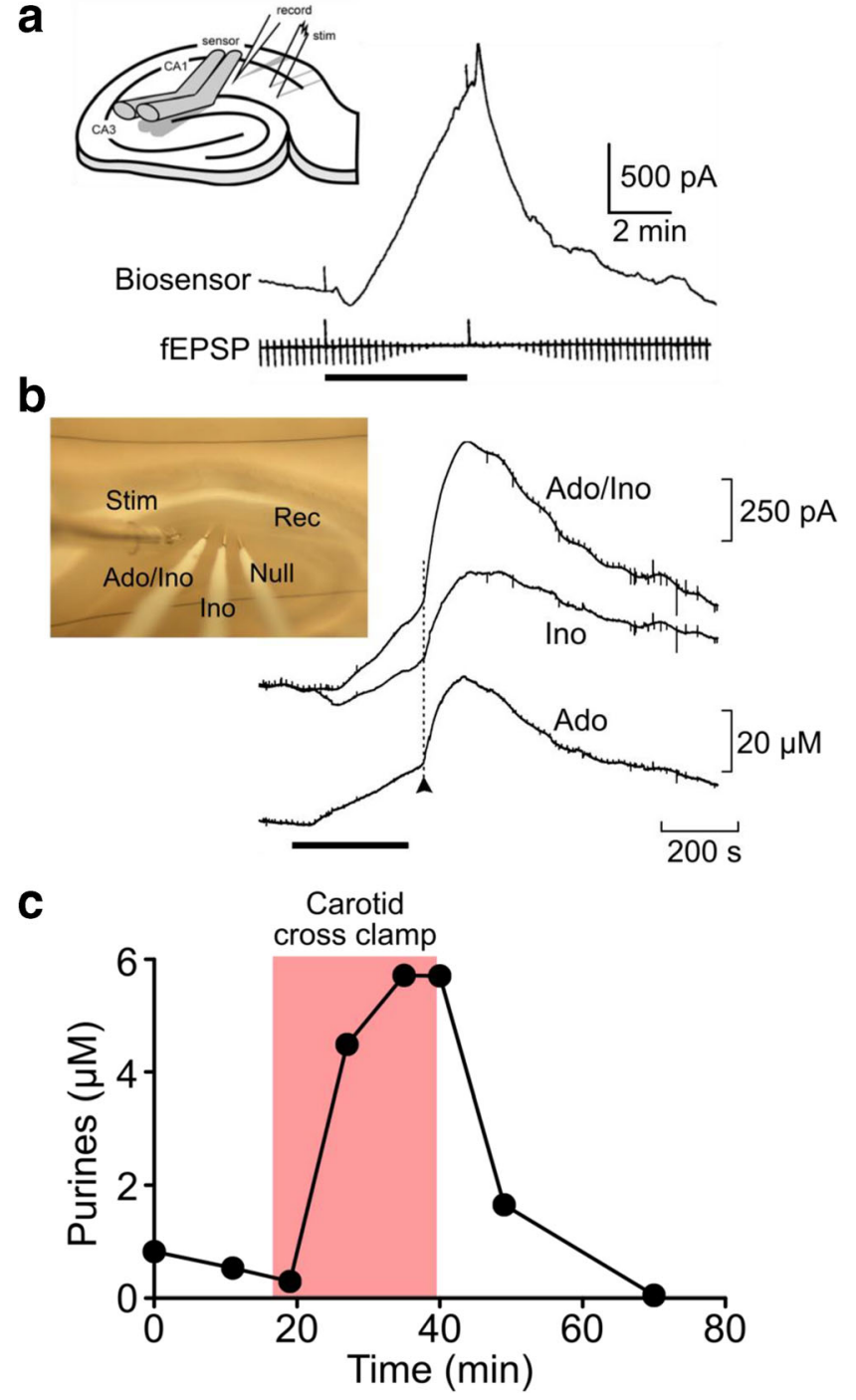

Fig. 2 Measurement of adenosine release during hypoxia/ischaemia. (a) Real-time recording of adenosine release from a hippocampal brain slice during a hypoxic episode (black bar). Synaptic transmission was recorded simultaneously (fEPSP). The inset shows the recording arrangement; this was made with the same type of microdialysis electrode as show in Fig. 1, except that it had two barrels which could be loaded with different enzyme combinations. Reproduced from [17]. (b) Microelectrode biosensor recordings of adenosine release during hypoxia (black bar). The inset shows a picture of the biosensors inserted into a hippocampal slice (the shiny metallic portion within the slice is the sensing tip). Measurement of purine release within the slice showed new features such as the post-hypoxic purine efflux (occurring at arrow head). Differential measurements between a biosensor with all three enzymes (Ado/Ino) and one only having PNPase and XO (Ino) allowed specific recording of the adenosine signal (Ado). Reproduced from [18]. (c) Measurement of purines (combination of adenosine, inosine, hypoxanthine) in arterial blood of a patient undergoing carotid endarterectomy. Note that purines are rapidly released from the brain when the carotid artery is cross clamped (pink box). Reproduced from [19]

adenosine biosensor used a microdialysis assembly with the enzymes being present in aqueous solution. I reasoned that if we stuck the enzymes directly to the electrode (by 
some as yet unknown method), we would have a much better, smaller, and more robust device.

After exploring the biosensor literature, I decided to follow the work of Serge Cosnier [21] and utilize the pyrrole derivatives he had described to make a microelectrode biosensor for adenosine. This required organic synthesis and led to Enrique Llaudet joining the team to make the pyrrole derivatives and fabricate the biosensors [22]. We used these methods for about 3 years but eventually replaced them with a silicate sol gel methodology that we invented and which gave more reliable and sensitive biosensors [23]. In fact, it was our development of the sol gel techniques that made it viable to set up a company, Sarissa Biomedical Ltd., to make and sell biosensors to the scientific community, as by now I had far more people wishing to use these biosensors than I could possibly collaborate with.

The microelectrode biosensors allowed us to place the biosensors inside the tissue. This gave important new insights into the production of purines during stroke-like conditions. We were able to demonstrate that in this case (unlike the tadpole spinal cord), adenosine was released directly and did not arise from prior release of ATP [24]. We refined our understanding of the temporal relationship between adenosine production and its effect on synaptic transmission and found that not only was there progressive release of adenosine during the ischemic episode but that reoxygenation of the tissue greatly accelerated purine release [18, 24] (Fig. 2b). This had not been well described before, but might contribute to the phenomenon of reactive hyperaemia [25] or indeed reperfusion injury [26], as the enhanced purine release would give rise to increased free radical production via $\mathrm{H}_{2} \mathrm{O}_{2}$ from the actions of endogenous xanthine oxidase.

By now we realized that the release of purines during in vitro stroke models might be paralleled by similar observations in the human brain during actual strokes and that adenosine and the purines might serve as sensitive indicators of human cerebral ischemia. However, the biosensors that we used for the physiological experiments were not sufficiently selective for measuring purines in blood, meaning that they were not suitable for any clinical studies. To address this issue, Faming Tian and I developed a next-generation biosensor that had an electrochemical mediator to provide excellent selectivity against electroactive interferences in blood opening the way for clinical applications [27]. Sarissa Biomedical has proven crucial in developing the technology further and thus providing a way to translate our advances in purine biosensing into practical applications. In 2017, via a collaboration with Chris Imray, a vascular surgeon at the University Hospitals of Coventry and Warwickshire, we showed that purines are released from the brain and detectable in the arterial blood of patients undergoing elective carotid artery surgery (and hence subjected to temporary unilateral cerebral hypoxia/ischaemia) [19] (Fig. 2c). A first trial of a very early prototype purine biosensing device "SMARTCap" showed, in a reasonably large cohort, that the purines of stroke patients are elevated compared with healthy controls and patients with mimicking nonstroke conditions [28]. Further trials of the latest prototype device "SMARTChip" are continuing to test the diagnostic accuracy of purines as an aid to detecting stroke.

\section{Microelectrode biosensors for ATP: chemosensory control of breathing}

My continued collaboration with Mike Spyer provided a spur to develop a biosensor for ATP. As Mike had obtained evidence that linked ATP signalling to the chemosensory control of breathing [29, 30], the ability to measure ATP release from the chemosensory nuclei in the medulla oblongata was an urgent priority. In developing an ATP biosensor, I had determined that the enzymatic cascade glycerol kinase and glycerol-3-phosphate oxidase would be advantageous (Fig. 3a) [34]. This cascade is sensitive to ATP, if glycerol is provided in the medium, and over the course of many studies, we have found that a concentration of glycerol sufficient to saturate the enzyme is well tolerated by tissue. However, we found it very difficult to find conditions that allowed entrapment of these enzymes on a microelectrode while retaining sufficient sensitivity to make a useful ATP biosensor. We eventually solved this problem with our new sol gel deposition method [35], and returned to work with Mike Spyer, who had now been joined by Alex Gourine, on the problem of $\mathrm{CO}_{2}$ chemosensitivity and the control of breathing.

Very quickly, we found that during a hypercapnic episode, ATP was released from proscribed areas of the ventral medullary surface that corresponded to the regions that had been linked to $\mathrm{pH} / \mathrm{CO}_{2}$ chemosensitivity [31]. Crucially the ATP was released before any adaptive change in breathing, suggesting a causal role between ATP release and the increase in minute ventilation (Fig. $3 b)$. This causal relation was confirmed through use of ATP receptor antagonists [31]. Subsequent work on this problem by Alex Gourine has highlighted an important role of astrocytes in the detection of $\mathrm{pH}$ and subsequent release of ATP [36, 37]. In my lab, we looked further at the mechanisms of ATP release and identified that this occurred through hemichannels of the gap junction protein connexin26 (Cx26) (Fig. 3c). We were able to link $\mathrm{Cx} 26$ to the chemosensory control of breathing with pharmacological tools [32]. However, we found that $\mathrm{Cx} 26$ seemed to respond directly to $\mathrm{CO}_{2}$ rather than $\mathrm{pH}[32$, 33]. Subsequent mutational analysis revealed the key residues involved and a potential mechanism that involved a proposed carbamylation of a specific lysine residue in $\mathrm{Cx} 26$ by $\mathrm{CO}_{2}$ [38]. $\mathrm{Cx} 26$ is thus a $\mathrm{CO}_{2}$-gated channel capable of releasing ATP. We have recently used our 
a

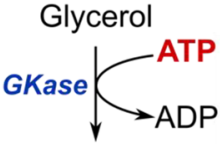

Glycerol-3-phosphate

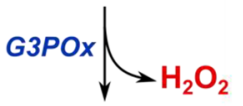

Glyerone phosphate b

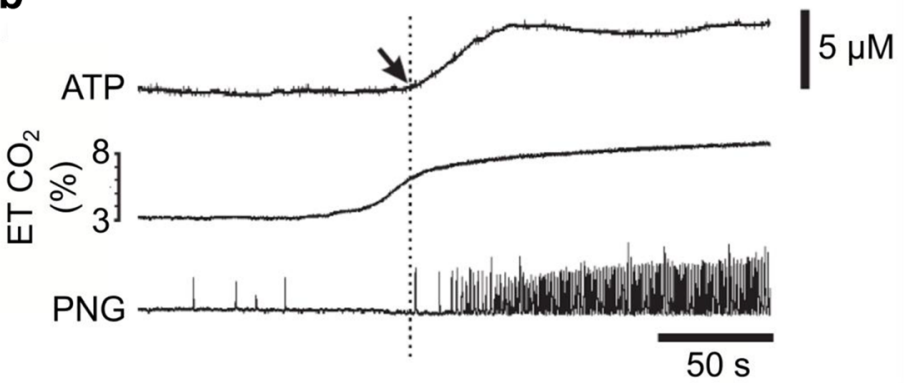

C
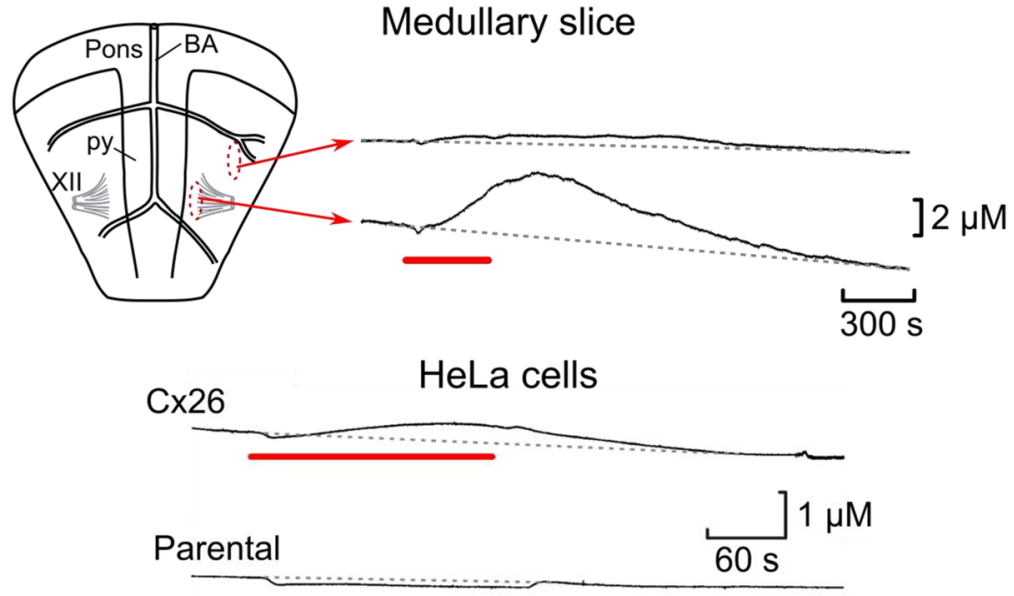

Fig. 3 Real-time measurement of ATP release with ATP microelectrode biosensors. (a) Enzymatic cascade for the detection of ATP. GKase, glycerol kinase; G3Pox, glycerol-3-phosphate oxidase. This cascade is sensitive only to ATP if glycerol concentrations are at least $0.5 \mathrm{mM}$. (b) Measurement of ATP release during hypercapnia from the ventral surface of the medulla oblongata of anaesthetized artificially ventilated rat. Note that ATP release occurs before the enhancement of breathing as indicated by the phrenic nerve recording (PNG, arrow on ATP biosensor trace and dotted line). End tidal (ET) $\mathrm{CO}_{2}$ is also shown. Modified from [31]. (c) In vitro models of hypercapnic ATP release. Isolated ventral medullary slice showing ATP release from a caudal region located next to the pyramids (py) and XII ${ }^{\text {th }}$ nerve (XII), but not from a much more lateral position. BA -basilar artery. Modified from [32]. $\mathrm{CO}_{2}$-dependent ATP release can be recapitulated in HeLa cells that express connexin26 (Cx26) but nor parental HeLa cells that do not express this connexin (modified from [33]). Red bars indicate period of hypercapnia (60 $\left.\mathrm{mmHg} \mathrm{PCO}_{2}\right)$ structural understanding of how $\mathrm{CO}_{2}$ interacts with $\mathrm{Cx} 26$ to develop a dominant negative construct that coassembles with endogenous wild-type Cx26 to remove $\mathrm{CO}_{2}$ sensitivity from the resulting heteromeric channel [39]. This genetic approach has allowed us to demonstrate that direct $\mathrm{CO}_{2}$ detection via $\mathrm{Cx} 26$ contributes about half of the adaptive response to hypercapnia generated by the central chemosensors. There is a population of specialized glial cells present in a circumscribed nucleus - the caudal parapyramidal area that directly detect $\mathrm{CO}_{2}$ via $\mathrm{Cx} 26$ and regulate breathing via the release of ATP [39]. Very recently, we have taken this down to the atomic level by solving cryoEM structures for Cx26 at different levels of $\mathrm{PCO}_{2}$ to directly demonstrate the carbamylation mechanism and understand the conformational changes trigged by $\mathrm{CO}_{2}$-binding that lead to channel gating [40].

In giving this personal account, I have tried to show that, like all great scientists, Geoff's work had far reaching effects on the science of others. For me, it is how Geoff's inspirational lecture some 26 years ago, and his larger than life effect on the field of purinergic signalling, inspired me to follow an interlinked thread of scientific exploration. At one end of the scientific spectrum, this initial spark led to development of biosensors to analyze purine release and now extends to their application in the clinical diagnosis of stroke, and at the other end of the spectrum, a sub-2 $\AA$ structure of the protein that acts as a receptor for $\mathrm{CO}_{2}$ can release ATP in response to fluctuations of $\mathrm{PCO}_{2}$ and plays a key role in vertebrate physiology.

Acknowledgments I thank Profs Mike Spyer and Bruno Frenguelli for commenting on a draft of this article.

Funding This work has been supported over many years by the Royal Society, the Biotechnology and Biological Sciences Research Council, and the Medical Research Council.

\section{Compliance with ethical standards}

Conflict of interest The author is the founder of Sarissa Biomedical Ltd. and holds equity in that company. 
Ethical approval This article does not contain any studies with human participants or animals performed by any of the authors.

Open Access This article is licensed under a Creative Commons Attribution 4.0 International License, which permits use, sharing, adaptation, distribution and reproduction in any medium or format, as long as you give appropriate credit to the original author(s) and the source, provide a link to the Creative Commons licence, and indicate if changes were made. The images or other third party material in this article are included in the article's Creative Commons licence, unless indicated otherwise in a credit line to the material. If material is not included in the article's Creative Commons licence and your intended use is not permitted by statutory regulation or exceeds the permitted use, you will need to obtain permission directly from the copyright holder. To view a copy of this licence, visit http://creativecommons.org/licenses/by/4.0/.

\section{References}

1. Dale N, Gilday D (1996) Regulation of rhythmic movements by purinergic neurotransmitters in frog embryos. Nature. 383(6597): 259-263

2. Zimmermann H (1996) Biochemistry, localization and functional roles of ecto-nucleotidases in the nervous system. Prog Neurobiol 49(6):589-618

3. Gordon EL, Pearson JD, Slakey LL (1986) The hydrolysis of extracellular adenine nucleotides by cultured endothelial cells from pig aorta. Feed-forward inhibition of adenosine production at the cell surface. J Biol Chem 261(33):15496-15507

4. Slakey LL, Cosimini K, Earls JP, Thomas C, Gordon EL (1986) Simulation of extracellular nucleotide hydrolysis and determination of kinetic constants for the ectonucleotidases. J Biol Chem 261(33): 15505-15507

5. James S, Richardson PJ (1993) Production of adenosine from extracellular ATP at the striatal cholinergic synapse. J Neurochem 60(1):219-227

6. Dale N (1998) Delayed production of adenosine underlies temporal modulation of swimming in frog embryo. J Physiol Lond 511(Pt 1): 265-272

7. Dale N (2002) Resetting intrinsic Purinergic modulation of neural activity: an associative mechanism? J Neurosci 22(23):1046110469

8. Winn HR, Rubio R, Berne RM (1979) Brain adenosine production in the rat during 60 seconds of ischemia. Circ Res 45(4):486-492

9. Van Wylen DG, Park TS, Rubio R, Berne RM (1986) Increases in cerebral interstitial fluid adenosine concentration during hypoxia, local potassium infusion, and ischemia. J Cereb Blood Flow Metab 6(5):522-528. https://doi.org/10.1038/jcbfm. 1986.97

10. Hillered L, Hallstrom A, Segersvard S, Persson L, Ungerstedt U (1989) Dynamics of extracellular metabolites in the striatum after middle cerebral artery occlusion in the rat monitored by intracerebral microdialysis. J Cereb Blood Flow Metab 9(5):607-616. https://doi.org/10.1038/jcbfm.1989.87

11. Rudolphi KA, Schubert P, Parkinson FE, Fredholm BB (1992) Adenosine and brain ischemia. Cerebrovasc Brain Metab Rev 4(4):346-369

12. Fowler JC (1993) Purine release and inhibition of synaptic transmission during hypoxia and hypoglycemia in rat hippocampal slices. Neurosci Lett 157(1):83-86

13. Phillis JW, Smith-Barbour M, O'Regan MH, Perkins LM (1994) Amino acid and purine release in rat brain following temporary middle cerebral artery occlusion. Neurochem Res 19(9):1125-1130

14. Zhao H, Asai S, Kanematsu K, Kunimatsu T, Kohno T, Ishikawa K (1997) Real-time monitoring of the effects of normothermia and hypothermia on extracellular glutamate re-uptake in the rat following global brain ischemia. Neuroreport. 8(9-10):2389-2393

15. Latini S, Bordoni F, Corradetti R, Pepeu G, Pedata F (1998) Temporal correlation between adenosine outflow and synaptic potential inhibition in rat hippocampal slices during ischemia- like conditions. Brain Res 794(2):325-328

16. Melani A, Pantoni L, Corsi C, Bianchi L, Monopoli A, Bertorelli R, Pepeu G, Pedata F (1999) Striatal outflow of adenosine, excitatory amino acids, gamma-aminobutyric acid, and taurine in awake freely moving rats after middle cerebral artery occlusion: correlations with neurological deficit and histopathological damage. Stroke. 30(11): 2448-2454 discussion 55

17. Dale N, Pearson T, Frenguelli BG (2000) Direct measurement of adenosine release during hypoxia in the CA1 region of the rat hippocampal slice. J Physiol-London 526(1):143-155

18. Frenguelli BG, Llaudet E, Dale N (2003) High-resolution real-time recording with microelectrode biosensors reveals novel aspects of adenosine release during hypoxia in rat hippocampal slices. $\mathrm{J}$ Neurochem 86(6):1506-1515

19. Tian F, Bibi F, Dale N, Imray CHE (2017) Blood purine measurements as a rapid real-time indicator of reversible brain ischaemia. Purinergic Signal 13:521-528. https://doi.org/10.1007/s11302017-9578-z

20. Pearson T, Nuritova F, Caldwell D, Dale N, Frenguelli BG (2001) A depletable pool of adenosine in area CA1 of the rat hippocampus. J Neurosci 21(7):2298-2307

21. Cosnier S (1997) Electropolymerization of amphiphilic monomers for designing amperometric biosensors. Electroanalysis. 9(12): 894-902

22. Llaudet E, Botting NP, Crayston JA, Dale N (2003) A threeenzyme microelectrode sensor for detecting purine release from central nervous system. Biosens Bioelectron 18(1):43-52

23. Dale N, Llaudet E, Droniou M (2003) Sol-gel biosensors. European Patent Number EP 1565565 B1

24. Frenguelli BG, Wigmore G, Llaudet E, Dale N (2007) Temporal and mechanistic dissociation of ATP and adenosine release during ischaemia in the mammalian hippocampus. J Neurochem 101(5): $1400-1413$

25. Zhou X, Teng B, Tilley S, Mustafa SJ (2013) A1 adenosine receptor negatively modulates coronary reactive hyperemia via counteracting A2A-mediated $\mathrm{H} 2 \mathrm{O} 2$ production and KATP opening in isolated mouse hearts. Am J Physiol Heart Circ Physiol 305(11): H1668-H1H79. https://doi.org/10.1152/ajpheart.00495.2013

26. White BC, Sullivan JM, DeGracia DJ, O'Neil BJ, Neumar RW, Grossman LI et al (2000) Brain ischemia and reperfusion: molecular mechanisms of neuronal injury. J Neurol Sci 179(S 1-2):1-33

27. Tian F, Llaudet E, Dale N (2007) Ruthenium purple-mediated microelectrode biosensors based on sol-gel film. Anal Chem 79(17): 6760-6766. https://doi.org/10.1021/ac070822f

28. Dale N, Tian F, Sagoo R, Phillips N, Imray C, Roffe C (2019) Point-of-care measurements reveal release of purines into venous blood of stroke patients. Purinergic Signal 15:237-246. https://doi. org/10.1007/s11302-019-09647-4

29. Thomas T, Spyer KM (2000) ATP as a mediator of mammalian central $\mathrm{CO}_{2}$ chemoreception. J Physiol 523(2):441-447

30. Thomas T, Ralevic V, Bardini M, Burnstock G, Spyer KM (2001) Evidence for the involvement of purinergic signalling in the control of respiration. Neuroscience. 107(3):481-490

31. Gourine AV, Llaudet E, Dale N, Spyer KM (2005) ATP is a mediator of chemosensory transduction in the central nervous system. Nature. 436(7047):108-111. https://doi.org/10.1038/nature03690

32. Huckstepp RT, Bihi R i, Eason R, Spyer KM, Dicke N, Willecke K et al (2010) Connexin hemichannel-mediated $\mathrm{CO}_{2}$-dependent release of ATP in the medulla oblongata contributes to central respiratory chemosensitivity. J Physiol 588(Pt 20):3901-3920. https:// doi.org/10.1113/jphysiol.2010.192088 
33. Huckstepp RT, Eason R, Sachdev A, Dale N (2010) $\mathrm{CO}_{2}$-dependent opening of connexin 26 and related beta connexins. J Physiol 588(Pt 20):3921-3931. https://doi.org/10.1113/jphysiol.2010. 192096

34. Albery WJ, Galley PT, Murphy LJ (1993) A dialysis electrode for glycerol. J Electroanal Chem 344(1-2):161-166

35. Llaudet E, Hatz S, Droniou M, Dale N (2005) Microelectrode biosensor for real-time measurement of ATP in biological tissue. Anal Chem 77(10):3267-3273

36. Gourine AV, Kasymov V, Marina N, Tang F, Figueiredo MF, Lane S, Teschemacher AG, Spyer KM, Deisseroth K, Kasparov S (2010) Astrocytes control breathing through $\mathrm{pH}$-dependent release of ATP. Science. 329(5991):571-575. https://doi.org/10.1126/science. 1190721

37. Turovsky E, Theparambil SM, Kasymov V, Deitmer JW, Del Arroyo AG, Ackland GL et al (2016) Mechanisms of $\mathrm{CO}_{2} / \mathrm{H}^{+}$ sensitivity of astrocytes. J Neurosci 36(42):10750-10758. https:// doi.org/10.1523/JNEUROSCI.1281-16.2016
38. Meigh L, Greenhalgh SA, Rodgers TL, Cann MJ, Roper DI, Dale N (2013) $\mathrm{CO}_{2}$ directly modulates connexin 26 by formation of carbamate bridges between subunits. eLife. 2:e01213. https://doi.org/10. 7554/eLife.01213

39. van de Wiel J, Meigh L, Bhandare A, Cook J, Nijjar S, Huckstepp RT, Dale N (2020) Connexin26 mediates $\mathrm{CO}_{2}$-dependent regulation of breathing via glial cells of the medulla oblongata. Communications Biology. https://doi.org/10.1038/s42003-02001248-x

40. Brotherton DH, Savva C, Ragan T, Linthwaite V, Cann M, Dale N, et al. Conformational changes and channel gating induced by $\mathrm{CO}_{2}$ binding to Connexin26. bioRxiv. 2020:2020.08.11.243964. https:// doi.org/10.1101/2020.08.11.243964

Publisher's note Springer Nature remains neutral with regard to jurisdictional claims in published maps and institutional affiliations. 